\title{
Use of xenogenous bone substitutes simultaneously to implant placement: literature review
}

\author{
Bernardo Olsson $^{1}$, Katheleen Miranda Dos Santos ${ }^{2}$, Paola Fernanda de Lucas Cotait Corso ${ }^{2}$, \\ Aline Monise Sebastiani ${ }^{1,2}$, Leandro Eduardo Klüppel ${ }^{1,2}$, Rafaela Scariot ${ }^{1,2}$, Guilherme Trento ${ }^{2}$ \\ ${ }^{1}$ Department of Oral and Maxillofacial Surgery, Federal University of Paraná, Curitiba, Paraná, Brazil; ${ }^{2}$ Division of Oral and Maxillofacial Surgery, \\ Cleft Lip and Palate Integral Care Center, Curitiba, Parana, Brazil \\ Contributions: (I) Conception and design: All authors; (II) Administrative support: B Olsson, G Trento; (III) Provision of study materials or patients: \\ All authors; (IV) Collection and assembly of data: B Olsson, G Trento; (V) Data analysis and interpretation: All authors; (VI) Manuscript writing: All \\ authors; (VII) Final approval of manuscript: All authors. \\ Correspondence to: Guilherme Trento. Division of Oral and Maxillofacial Surgery, Cleft Lip and Palate Integral Care Center, $4334^{\text {th }}$ Republica \\ Argentina Avenue, Curitiba, Parana, Brazil. Email: guilhermetrento@yahoo.com.br.
}

Background and Objective: The relentless pursuit of alternative materials for autogenous bonegraft made several research groups develop different kinds of bone substitute materials as well as different techniques. The use of xenogenous bonegrafts are a reality and studies already have shown their safety, providing satisfactory results when compared to autogenous grafts. The lack of donor site morbidity in the use of such bone substitute materials added to the convenience and their properties led them to be a great choice for different techniques for augmentation. The objective of this study was to perform a literature review over clinical studies about the use of xenogenous bone substitutes simultaneously with the installation of implants.

Methods: The search strategy was performed in MEDLINE database scanning the subjects of interest using three different descriptors: "dental implants"; “immediate”; "bone substitute materials". Two hundred and fifty-eight records were identified through database and other sources searching. No duplicates were identified; thus 258 records were screened. After applying the inclusion criteria, 222 records were excluded and 36 records were included in the qualitative analysis.

Key Content and Findings: Although the majority of studies did not have as the main objective to evaluate the quality of osseointegration, it was possible to presume that the success rates of implants installed simultaneously with bone substitute materials are high (over than 90\%). Moreover, the use of bone substitute materials has several indications such as to fulfill gaps, to increase implant stability, to maintain vertical and horizontal dimension of alveolar crest, and, in some cases, to improve osseointegration.

Conclusions: Although the majority of studies did not have as the main objective to evaluate the quality of osseointegration, it was possible to presume that the success rates of implants installed simultaneously with bone substitute materials are high (over than 90\%) and can be considered a valuable and feasible technique. Moreover, the use of bone substitute materials has several indications such as to fulfill gaps, to increase implant stability, to maintain vertical and horizontal dimension of alveolar crest, and, in some cases, to improve osseointegration.

Keywords: Dental implants; immediate; bone substitute materials

Received: 30 March 2021; Accepted: 09 October 2021; Published online: 19 October 2021.

doi: $10.21037 /$ fomm-21-41

View this article at: https://dx.doi.org/10.21037/fomm-21-41 


\section{Introduction}

Among the rehabilitation techniques for missing teeth, the use of dental implants is very popular due to its predictability, security and durability (1). Depending on the cause or the time elapsed since the tooth loss, the site for the implant installation may not be adequate due to bone loss in height and/or thickness, thus requiring some form of reconstruction by means of bone grafting prior to or simultaneously with the implant installation $(2,3)$.

Lately, the pursue for faster oral rehabilitation by patients, surgeons and researchers had shown different treatment planning options that aimed to decrease the time and the number of surgical procedures. One of these techniques consists in the dental implant placement in the fresh extraction socket. However, the dental implant itself is not capable to fill the whole socket being indicated the use of bonegraft $(4,5)$.

The advantages of guided bone regeneration (GBR) simultaneously with the implant placement are to submit the patient to only one surgical procedure, less morbidity, lower rate of complications and faster completion of treatment $(6,7)$.

Among the functions and benefits of the use of bonegrafts are: augmentation of the alveolar ridge providing enough bone height and width to dental implant insertion; maintenance or reconstruction of the alveolar crest mainly in aesthetics regions; filling of the fresh extraction socket providing stability both to the dental implant placed immediately and to the blood clot (8-10).

In these cases, what should be taken into account is the type of bone graft indicated $(6,11)$. Due to its osteoconductive, osteoinductive and osteogenic properties, autogenous bone is considered the gold standard (12). However, aiming at a surgical procedure with less morbidity, xenogenous bone substitutes have an excellent indication since they have a low resorption rate and good osteoconductivity $(6,7)$. Studies have shown that xenogenous bone substitutes are safe and provide satisfactory results when compared to autogenous grafts $(6,13)$.

It is important that the surgeon knows when to indicate and when to contraindicate the use of xenogenous bone substitutes simultaneously with the implant installation procedure. Therefore, this article aims to review clinical studies involving the use of xenogenous bone substitutes simultaneously with the installation of implants. The following article is in accordance with the Narrative Review reporting checklist (available at https://fomm.amegroups. com/article/view/10.21037/fomm-21-41/rc).

\section{Methods}

The search strategy of this literature review was performed in MEDLINE (Medical Literature Analysis and Retrieval System Online, via PubMed) database scanning the subjects of interest using three descriptors: "dental implants"; "immediate"; "bone substitute materials".

The initial selection and analyze of titles and/or abstracts were performed by three independent reviewers (BO, GST, KMS) and according to the following inclusion criteria: specific studies that evaluated the use of bone substitute materials (xenograph only) simultaneously to dental implants installation; studies on humans and only and reported in English language without time restriction regarding to publication date; and case series, retrospective or prospective clinical design. Assuming general results, the inclusion criteria were performed without specifying the type of dental implants, and quantity of bone substitute material. Only articles that used xenographs were included in this study. The separation from other sources of bone substitutes (autogenous, allogenic and alloplastic graphs) was performed by title, abstract and full text analysis.

After initial selection according to inclusion criteria, full-text reading was performed to define which studies to include. Reviewers solved any disagreements performing additional discussion among them.

Data extraction were performed including the following variables: study design; number of patients, age and gender; type of bone substitute material; type of dental implant; treatment and success rate. Again, disagreements between reviewers were solved by further discussion. Data were analyzed by descriptive statistics.

\section{Results}

Two hundred and fifty-eight records were identified through database and other sources searching. No duplicates were identified; thus 258 records were screened. After applying the inclusion criteria, 224 records were excluded and 34 records were included in the qualitative analysis (Figure 1) (14).

The included articles were published from 2000 to 2019 . The range of patient's age was 17 to 83 years old (15). Twenty-one studies had a comparator group (16-36). The majority of the included studies were interventional and prospective and most of them used particulate bone grafts 

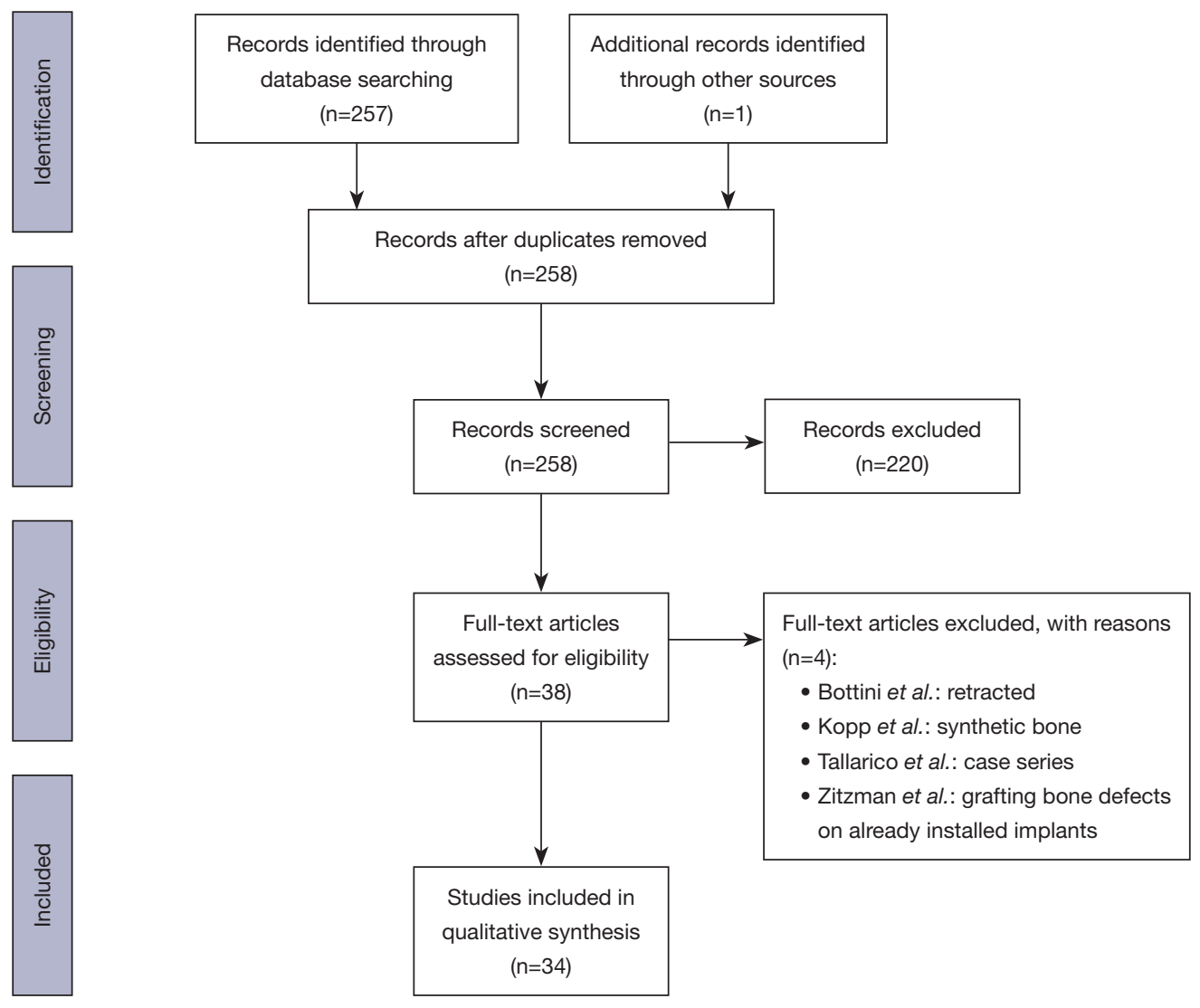

Figure 1 Summary of the screening and selection process of the studies. From: Moher et al. (14).

alone $(15,24,25,28,30,32,34-39)$ or a mix with autologous bone $(20,31,40)$, while some used bone blocks $(35,41)$. Most implants and bone grafts were placed in maxilla, either in anterior region $(29,34,42,43)$ or for sinus augmentation (17-19,31,32,38,40,41). Clinical, radiographic and histological outcomes have been reported. The follow-up time ranges from 4 months (44) to 9 years (40).

Of all studies included in this literature review, 17 involved only maxilla $(18,20-22,25,27,29,31,32,34,37,38,40-44)$, 2 involved only mandible $(26,39)$, and 9 involved both maxilla and mandible $(15-17,24,28,30,35,36,45)$. Just the study from Zumstein \& Sennerby (17) performed sinus lifting and postextraction implants in the same methodology. Fifteen were based on postextraction technique (15,19-21,24-26,28,30,34,39,42-45) and 8 were based on sinus lifting technique $(17-19,31,32,38,40,41)$. Twenty used Bio-Oss as the bone substitute material $(15,16,18,22,24,25,27-31,34-41,44,45)$, and different types of implant were used. Regarding the prescription, 10 studies reported the use of prophylactic antibiotic administration
$(15-18,20,25,29,30,35,36,44)$.

\section{Discussion}

As case control, cohort, and randomized controlled studies are on the top of evidence-based pyramid, it was opted to include only this kind of studies. Furthermore, the main objective of this study was to clarify if the use of bone substitute materials affects the osseointegration of dental implants. Although the majority of studies included did not have the same objective as this one, it was possible to determine that the use of substitute bone materials can be very helpful to the patient treatment at all.

A multicenter controlled randomized trial (25) was performed to evaluate the outcome of implants (tioLogic implant System) placed immediately after maxillary premolar extraction. One hundred and two patients were divided into two groups: with or without bone substitute material. Granular bone grafting was inserted (BioOss, Geistlich) and completely covered by a pericardium 
membrane (Osteobiol Evolution, Tecnoss). A total of 113 implants completed the 3-year follow-up (one implant from each group failed). Implants overall survival rate was $99.1 \%$ at 12 months and $98.3 \%$ at 3 years. The authors concluded that the use of anorganic bovine bone substitute with a resorbable collagen barrier in immediate postextractive implants seems to improve the esthetic outcomes after a 3 -year follow-up.

Another study that installed immediate implants only in maxilla was the performed by Sanz-Martín et al. (42). Eighty-six patients were included in this randomized controlled parallel-group study in which 86 implants (Fixture Microthread Ossseospeed, Dentsply) were immediately placed in the anterior maxilla. The test group was formed by grafting with demineralized bovine bone mineral with $10 \%$ collagen (DBBM-C, Bio Oss) in the gap between the implant surface and the inner bone walls. No graft was used for the control group. After 16 weeks, the success rate was $100 \%$. In conclusion, the results from this short-term hard tissue changes study demonstrated that grafting bone substitute material such as DDBM-C significantly reduced the horizontal bone resorptive changes occurring in the buccal bone after the immediate implantation in fresh extraction sockets.

Following the same line, van Steenberghe et al. (15) performed a prospective clinical study with 15 patients. Twenty-one implants (Branemark system - Nobel Biocare $\mathrm{AB})$ were immediately installed after extraction. Granules of deproteinized bovine bone of $0.25-1.0 \mathrm{~mm}$ diameter were used to fill the remaining defect when the distance of the defect wall to the implant surface was $\pm 3 \mathrm{~mm}$. Implants were placed both in maxilla and mandible. After 12 months, no implant losses were observed. The authors concluded that the present results indicate that deproteinized bovine bone is a safe filling material to fill remaining defects around implants installed in fresh extraction sockets. Moreover, the authors stated that exposure of the granules does not lead to inflammatory or infectious soft tissue reactions.

Li et al. (26) performed also a prospective clinical study involving patients diagnosed with severe periodontitis of the posterior mandibular tooth and agreed to dental implant treatment (ITI Straumann). The patients were randomly divided into two groups: the DDM (dentine dental matrix) group, treated with immediate implantation and GBR with autogenous DDM granules from the extracted tooth; and the BIO group, treated with immediate implantation and GBR with Bio-Oss granules. After 18 months, 43 of 45 implants produced successful osseointegration.
This study showed a similar clinical and radiographic performance of DDM and traditional osseous powder in immediate placement of implants in periodontal postextraction sites. The autogenous DDM granules acted as an excellent, readily available alternative to bone graft material in GBR, even for implantation in severe periodontitis cases.

Among the included studies that involved postextraction sites, De Angelis et al. (33) presented a success rate of 91\% and Vandeweghe et al. (45) presented 91.7\% (11 of 12 implants) when the use of Bio Oss. These studies were the ones that presented the lower success rates. According to authors of both studies, although the success rates are lower in comparison to other studies, the results are favorable to the use of bone substitute materials in defects around postextractive implant.

Regarding studies that performed sinus augmentation and implant placement, different methodologies were found: bone blocks (41), particulate bone $(27,38)$ and mixture of autologous and xenographs in a 1:1 (31) proportion and 2:1 (40) proportion.

One study used bovine-HA spongiosa blocks in sinus augmentation procedure with simultaneous implant placement (41). The authors performed a follow-up of 12 months in 10 patients and concluded that the procedure is predictable regarding osseointegration. Histologically, the authors proved that bone blocks are a suitable graft material for sinus augmentation because new bone was found. Moreover, bone blocks provide initial stability, which ease implant placement.

Özkan et al. (38) performed a clinical and radiographic study in 28 patients, which were followed-up for 5 years. A success rate of $100 \%$ was achieved after 5 years. It was observed that marginal bone change was constant in this study, which is the opposite from what was found by Hatano et al. (40). This difference may have happened because the last one used a mixture of autologous bone and xenograph, and it is known that autologous bone have higher resorption rates (46). The success rate of Hatano et al. (40) and Özkan et al. (38) was also different, 94\% vs. $100 \%$, respectively. The technique for sinus augmentation can not be responsible for this difference mainly because the follow-up of both studies were also different, 9 years (40) vs. 5 years (38).

Although the majority of studies did not have as the main objective to evaluate the quality of osseointegration, it was possible to presume that the success rates of implants installed simultaneously with bone substitute materials are high (over 
than $90 \%$ ) and can be considered a valuable and feasible technique. Moreover, the use of bone substitute materials is indicated to fulfill gaps, to increase implant stability, to maintain vertical and horizontal dimension of alveolar crest, and, in some cases, to improve osseointegration. After this research, it would be interesting to perform a systematic review aiming to aggregate studies with similar methodology to achieve more concrete conclusions.

\section{Acknowledgments}

Funding: None.

\section{Footnote}

Provenance and Peer Review: This article was commissioned by the Guest Editors (Valfrido Antônio Pereira-Filho and Pedro Carvalho) for the series "Xenogenous and Xenosynthetic Bone Substitutes: State-of-the-art and Clinical Outcomes" published in Frontiers of Oral and Maxillofacial Medicine. The article has undergone external peer review.

Reporting Checklist: The authors have completed the Narrative Review reporting checklist. Available at https://fomm. amegroups.com/article/view/10.21037/fomm-21-41/rc

Conflicts of Interest: All authors have completed the ICMJE uniform disclosure form. (available at https://fomm. amegroups.com/article/view/10.21037/fomm-21-41/ coif). The series "Xenogenous and Xeno-synthetic bone substitutes: State-of-the-art and Clinical Outcomes" was commissioned by the editorial office without any funding or sponsorship. The authors have no other conflicts of interest to declare.

Ethical Statement: The authors are accountable for all aspects of the work in ensuring that questions related to the accuracy or integrity of any part of the work are appropriately investigated and resolved.

Open Access Statement: This is an Open Access article distributed in accordance with the Creative Commons Attribution-NonCommercial-NoDerivs 4.0 International License (CC BY-NC-ND 4.0), which permits the noncommercial replication and distribution of the article with the strict proviso that no changes or edits are made and the original work is properly cited (including links to both the formal publication through the relevant DOI and the license).
See: https://creativecommons.org/licenses/by-nc-nd/4.0/.

\section{References}

1. Albrektsson T, Donos N; Working Group 1. Implant survival and complications. The Third EAO consensus conference 2012. Clin Oral Implants Res 2012;23 Suppl 6:63-5.

2. de Azambuja Carvalho PH, Dos Santos Trento G, Moura LB, et al. Horizontal ridge augmentation using xenogenous bone graft-systematic review. Oral Maxillofac Surg 2019;23:271-9.

3. De Stavola L, Tunkel J. A new approach to maintenance of regenerated autogenous bone volume: delayed relining with xenograft and resorbable membrane. Int $\mathrm{J}$ Oral Maxillofac Implants 2013;28:1062-7.

4. Cooper LF, Reside GJ, Raes F, et al. Immediate provisionalization of dental implants placed in healed alveolar ridges and extraction sockets: a 5 -year prospective evaluation. Int J Oral Maxillofac Implants 2014;29:709-17.

5. Atieh MA, Alsabeeha NH, Duncan WJ, et al. Immediate single implant restorations in mandibular molar extraction sockets: a controlled clinical trial. Clin Oral Implants Res 2013;24:484-96.

6. Pistilli R, Felice P, Piatelli M, et al. Blocks of autogenous bone versus xenografts for the rehabilitation of atrophic jaws with dental implants: preliminary data from a pilot randomised controlled trial. Eur J Oral Implantol 2014;7:153-71.

7. Schropp L, Wenzel A. Timing of single implant placement and long-term observation of marginal bone levels. Eur J Oral Implantol 2016;9 Suppl 1:S107-22.

8. Albrektsson T, Sennerby L, Wennerberg A. State of the art of oral implants. Periodontol 2000 2008;47:15-26.

9. Ortega-Martínez J, Pérez-Pascual T, Mareque-Bueno $\mathrm{S}$, et al. Immediate implants following tooth extraction. A systematic review. Med Oral Patol Oral Cir Bucal 2012;17:e251-61.

10. Verket A, Lyngstadaas SP, Tiainen H, et al. Impact of particulate deproteinized bovine bone mineral and porous titanium granules on early stability and osseointegration of dental implants in narrow marginal circumferential bone defects. Int J Oral Maxillofac Surg 2018;47:1086-94.

11. Dasmah A, Thor A, Ekestubbe A, et al. Particulate vs. block bone grafts: three-dimensional changes in graft volume after reconstruction of the atrophic maxilla, a 2-year radiographic follow-up. J Craniomaxillofac Surg 2012;40:654-9. 
12. Simion M, Jovanovic SA, Tinti C, et al. Long-term evaluation of osseointegrated implants inserted at the time or after vertical ridge augmentation. A retrospective study on 123 implants with 1-5 year follow-up. Clin Oral Implants Res 2001;12:35-45.

13. Al Ruhaimi KA. Bone graft substitutes: a comparative qualitative histologic review of current osteoconductive grafting materials. Int J Oral Maxillofac Implants 2001;16:105-14.

14. Moher D, Liberati A, Tetzlaff J, et al. Preferred reporting items for systematic reviews and meta-analyses: the PRISMA statement. PLoS Med 2009;6:e1000097.

15. van Steenberghe D, Callens A, Geers L, et al. The clinical use of deproteinized bovine bone mineral on bone regeneration in conjunction with immediate implant installation. Clin Oral Implants Res 2000;11:210-6.

16. Zumstein T, Billström C, Sennerby L. A 4- to 5-year retrospective clinical and radiographic study of Neoss implants placed with or without GBR procedures. Clin Implant Dent Relat Res 2012;14:480-90.

17. Zumstein T, Sennerby L. A 1-Year Clinical and Radiographic Study on Hydrophilic Dental Implants Placed with and without Bone Augmentation Procedures. Clin Implant Dent Relat Res 2016;18:498-506.

18. Yin L, Yu Z, Chen Z, et al. Analysis of Bone Height Changes after Maxillary Sinus Augmentation with Simultaneous and Delayed Placement of Dental Implants: A Clinical and Radiographic Study. J Prosthodont 2016;25:440-5.

19. Tawil G, Mawla M. Sinus floor elevation using a bovine bone mineral (Bio-Oss) with or without the concomitant use of a bilayered collagen barrier (Bio-Gide): a clinical report of immediate and delayed implant placement. Int J Oral Maxillofac Implants 2001;16:713-21.

20. Spinato S, Agnini A, Chiesi M, et al. Comparison between graft and no-graft in an immediate placed and immediate nonfunctional loaded implant. Implant Dent 2012;21:97-103.

21. Sanz M, Lindhe J, Alcaraz J, et al. The effect of placing a bone replacement graft in the gap at immediately placed implants: a randomized clinical trial. Clin Oral Implants Res 2017;28:902-10.

22. Nemcovsky CE, Artzi Z, Moses O, et al. Healing of marginal defects at implants placed in fresh extraction sockets or after 4-6 weeks of healing. A comparative study. Clin Oral Implants Res 2002;13:410-9.

23. Merli M, Moscatelli M, Mariotti G, et al. Comparing membranes and bone substitutes in a one-stage procedure for horizontal bone augmentation. Three-year post- loading results of a double-blind randomised controlled trial. Eur J Oral Implantol 2018;11:441-52.

24. Matarasso S, Salvi GE, Iorio Siciliano V, et al. Dimensional ridge alterations following immediate implant placement in molar extraction sites: a six-month prospective cohort study with surgical re-entry. Clin Oral Implants Res 2009;20:1092-8.

25. Mastrangelo F, Gastaldi G, Vinci R, et al. Immediate Postextractive Implants With and Without Bone Graft: 3-year Follow-up Results From a Multicenter Controlled Randomized Trial. Implant Dent 2018;27:638-45.

26. Li P, Zhu H, Huang D. Autogenous DDM versus BioOss granules in GBR for immediate implantation in periodontal postextraction sites: A prospective clinical study. Clin Implant Dent Relat Res 2018;20:923-8.

27. Kim SM, Park JW, Suh JY, et al. Bone-added osteotome technique versus lateral approach for sinus floor elevation: a comparative radiographic study. Implant Dent 2011;20:465-70.

28. Jung RE, Zaugg B, Philipp AO, et al. A prospective, controlled clinical trial evaluating the clinical radiological and aesthetic outcome after 5 years of immediately placed implants in sockets exhibiting periapical pathology. Clin Oral Implants Res 2013;24:839-46.

29. Jiang X, Zhang Y, Di P, et al. Hard tissue volume stability of guided bone regeneration during the healing stage in the anterior maxilla: A clinical and radiographic study. Clin Implant Dent Relat Res 2018;20:68-75.

30. $\mathrm{Hu} \mathrm{C}$, Lin W, Gong T, et al. Early Healing of Immediate Implants Connected With Two Types of Healing Abutments: A Prospective Cohort Study. Implant Dent 2018;27:646-52.

31. Galindo-Moreno P, León-Cano A, Ortega-Oller I, et al. Marginal bone loss as success criterion in implant dentistry: beyond $2 \mathrm{~mm}$. Clin Oral Implants Res 2015;26:e28-34.

32. Fouad W, Osman A, Atef M, et al. Guided maxillary sinus floor elevation using deproteinized bovine bone versus graftless Schneiderian membrane elevation with simultaneous implant placement: Randomized clinical trial. Clin Implant Dent Relat Res 2018;20:424-33.

33. De Angelis N, Felice P, Pellegrino G, et al. Guided bone regeneration with and without a bone substitute at single post-extractive implants: 1-year post-loading results from a pragmatic multicentre randomised controlled trial. Eur J Oral Implantol 2011;4:313-25.

34. Chen ST, Darby IB, Reynolds EC. A prospective clinical study of non-submerged immediate implants: clinical 
outcomes and esthetic results. Clin Oral Implants Res 2007;18:552-62.

35. Benic GI, Eisner BM, Jung RE, et al. Hard tissue changes after guided bone regeneration of peri-implant defects comparing block versus particulate bone substitutes: 6-month results of a randomized controlled clinical trial. Clin Oral Implants Res 2019;30:1016-26.

36. Benic GI, Ge Y, Gallucci GO, et al. Guided bone regeneration and abutment connection augment the buccal soft tissue contour: 3-year results of a prospective comparative clinical study. Clin Oral Implants Res 2017;28:219-25.

37. Schneider D, Grunder U, Ender A, et al. Volume gain and stability of peri-implant tissue following bone and soft tissue augmentation: 1-year results from a prospective cohort study. Clin Oral Implants Res 2011;22:28-37.

38. Özkan Y, Akoğlu B, Kulak-Özkan Y. Maxillary sinus floor augmentation using bovine bone grafts with simultaneous implant placement: a 5-year prospective follow-up study. Implant Dent 2011;20:455-9.

39. Hayacibara RM, Gonçalves CS, Garcez-Filho J, et al. The success rate of immediate implant placement of mandibular molars: a clinical and radiographic retrospective evaluation between 2 and 8 years. Clin Oral Implants Res 2013;24:806-11.

40. Hatano N, Shimizu Y, Ooya K. A clinical long-term radiographic evaluation of graft height changes after maxillary sinus floor augmentation with a 2:1 autogenous

doi: 10.21037/fomm-21-41

Cite this article as: Olsson B, Miranda Dos Santos K, Corso PFLC, Sebastiani AM, Klüppel LE, Scariot R, Trento G. Use of xenogenous bone substitutes simultaneously to implant placement: literature review. Front Oral Maxillofac Med 2023;5:6. bone/xenograft mixture and simultaneous placement of dental implants. Clin Oral Implants Res 2004;15:339-45.

41. Artzi Z, Nemcovsky CE, Dayan D. Bovine-HA spongiosa blocks and immediate implant placement in sinus augmentation procedures. Histopathological and histomorphometric observations on different histological stainings in 10 consecutive patients. Clin Oral Implants Res 2002;13:420-7.

42. Sanz-Martín I, Encalada C, Sanz-Sánchez I, et al. Soft tissue augmentation at immediate implants using a novel xenogeneic collagen matrix in conjunction with immediate provisional restorations: A prospective case series. Clin Implant Dent Relat Res 2019;21:145-53.

43. Bonnet F, Karouni M, Antoun H. Esthetic evaluation of periimplant soft tissue of immediate single-implant placement and provisionalization in the anterior maxilla. Int J Esthet Dent 2018;13:378-92.

44. Ramaglia L, Sbordone C, Saviano R, et al. Marginal masticatory mucosa dimensional changes in immediate post-extractive implants: a 2 year prospective cohort study. Clin Oral Implants Res 2015;26:1495-502.

45. Vandeweghe S, Hattingh A, Wennerberg A, et al. Surgical protocol and short-term clinical outcome of immediate placement in molar extraction sockets using a wide body implant. J Oral Maxillofac Res 2011;2:e1.

46. Peng W, Kim IK, Cho HY, et al. Assessment of the autogenous bone graft for sinus elevation. J Korean Assoc Oral Maxillofac Surg 2013;39:274-82. 